\title{
VI: ABKÜRZUNGEN UND SIGLEN
}

B

BdK

BeE

$\mathrm{Br}$

CollGerm

DTM

EiP

EPr

Fr

FZPhTh

IF

MTU

N1

N2

OIP

TuT

$\mathrm{U}$
$=$ Staatsbibliothek zu Berlin-PreuBischer Kulturbesitz, Ms. germ. qu. 167

$=$ Bibel und deutsche Kultur. Veröffentlichungen des Deutschen Bibel $=$ Archivs in Hamburg. Neue Folge der "Materialien zur Bibelgeschichte und religiösen Volkskunde des Mittelalters"

$=$ Berliner Evangelistar I: Staatsbibliothek zu Berlin - Preußischer Kulturbesitz, Ms. germ. $4^{\circ} 533$

$=$ Bremen, Staats- und Universitätsbibliothek, msa 0024

$=$ Colloquia Germanica. Internationale Zeitschrift für germanische Sprachund Literaturwissenschaft

$=$ Deutsche Texte des Mittelalters

$=$ Eifler Plenarhandschrift: Stadtbibliothek Trier, Cod. 810/1338 $4^{\circ}$

= Evangelien der guten Meister zu Prag: Staatsbibliothek Bamberg, Cod. Lit. 146

$=$ Frankfurt / Main, Stadtbibliothek, Ms. germ. qu. 55 (olim: Ms. II, 29)

$=$ Freiburger Zeitschrift für Philosophie und Theologie

$=$ Indogermanische Forschungen. Zeitschrift für Indogermanistik und Allgemeine Sprachwissenschaft

$=$ Münchener Texte und Untersuchungen zur deutschen Literatur des Mittelalters

$=$ Mitteilungen des Vereins für Geschichte der Stadt Nürnberg

= Nürnberg, Stadtbibliothek, Cod. Cent. V, App. 30 (olim: Cod. D XI)

= Nürnberg, Stadtbibliothek, Cod. Cent. VIII,2 (olim: Cod. D XIV)

= Olmützer Perikopen: Fürstlich-Fürstenbergsche Hofbibliothek Donaueschingen, Ms. 204

$=$ Texte und Textgeschichte

$=$ Staats- und Universitătsbibliothek Hamburg, Cod. theol. 1066 
VL $=$ Deutsche Literatur des Mittelalters. Verfasserlexikon. Begründet von WOLFGANG STAMMLER, fortgeführt von KARL LANGOSCH. Zweite, völlig neu bearbeitete Auflage unter Mitarbeit zahlreicher Fachgelehrter hrsg. von KURT RUH zusammen mit GUNDOLF KEIL, WERNER SCHRODER, BURGhart Wachinger, Franz JOSEF WORSTBROCK, Bd. 1ff., Berlin New York 1978ff.

ZBKG $=$ Zeitschrift für bayerische Kirchengeschichte

ZDA $=$ Zeitschrift für deutsches Altertum und deutsche Literatur 